\title{
On the Program of Russian Research in the Field of Controlled Thermonuclear Fusion and Plasma Technologies
}

\author{
V. I. Ilgisonis ${ }^{a, *}$, K. I. Ilyin ${ }^{b}$, S. G. Novikov ${ }^{a}$, and Yu. A. Olenin ${ }^{a}$ \\ a State Atomic Energy Corporation "Rosatom”, Moscow, 119017 Russia \\ ${ }^{b}$ State Research Center of the Russian Federation Troitsk Institute for Innovation and Fusion Research (TRINITI JSC), \\ Troitsk, Moscow, 108840 Russia \\ *e-mail:vilkiae@gmail.com \\ Received July 19, 2021; revised July 22, 2021; accepted July 22, 2021
}

\begin{abstract}
The main scientific problems solved within the "Development of controlled fusion technologies and innovative plasma technologies" federal project, part of the comprehensive program "Development of equipment, technologies, and scientific research in the field of atomic energy use in the Russian Federation for the period up to 2024" are described. A brief history of development of the project is given, and the description of its main components, participants, anticipated results, and possibilities for the future is presented. This paper is a foreword to the materials of the journal issue entirely devoted to the Tokamak with Reactor Technologies (TRT) project, which is to be developed within the federal project.
\end{abstract}

Keywords: thermonuclear fusion, tokamak, blanket, national project, federal project, plasma technologies

DOI: $10.1134 / \mathrm{S} 1063780 \mathrm{X} 21110179$

\section{INTRODUCTION}

Since the beginning of 2021, the Russian Federation has been implementing the comprehensive program "Development of equipment, technologies and scientific research in the field of atomic energy use in the Russian Federation for the period up to 2024" (hereinafter, the DETS Program). The DETS Program combines the most important activities in the field of scientific research and development of nuclear, thermonuclear, and related technologies, creation of new equipment, construction of innovative power units for high- and low-power nuclear power plants (NPPs), which are implemented by enterprises and institutes of nuclear industry in close cooperation with other leading Russian scientific and educational institutes and industrial enterprises.

Structurally, the DETS Program consists of five federal projects corresponding to the scientific and technical areas defined by the Decree of the President of the Russian Federation No. 270 dated April 16, 2020 "On the development of equipment, technologies, and scientific research in the field of atomic energy use in the Russian Federation" (hereinafter, Decree 270), namely [1]:

-development of two-component nuclear power technologies with a closed nuclear fuel cycle;

-development of controlled thermonuclear fusion and innovative plasma technologies;

-development of new materials and technologies for advanced energy systems;
- design and construction of reference power units of nuclear power plants, including small nuclear power plants.

An individual federal project is assigned to each direction of the Decree 270 on the DETS Program. Only the first direction of Decree 270 stands out including two federal projects: "Development of twocomponent nuclear power technologies with a closed nuclear fuel cycle" project akin to the "Proryv" project ("Breakthrough" project) in spirit and formulated tasks [2], and "Creation of a modern experimental and bench-based facility for development of two-component nuclear power technology with a closed nuclear fuel cycle" project providing, as its main components, the construction of the multi-purpose research fast ${ }^{1}$ reactor MBIR [3] and the extension of service life of the operating research fast reactor BOR-60 [4]. The availability of an operating research fast reactor with a high neutron flux is extremely important for testing and development of materials operating under conditions of neutron irradiation, in particular, in nuclear power plants or research facilities.

This paper briefly describes the range of tasks addressed by the third federal project "Development of controlled fusion and innovative plasma technologies" (hereinafter, FP-3) of the DETS Program and the main parameters of this federal project.

\footnotetext{
${ }^{1} \mathrm{~A}$ fast reactor is a nuclear reactor, whose core does not contain neutron moderators, and whose neutron spectrum is close to the energy of fission neutrons $(\sim 100 \mathrm{keV}-10 \mathrm{MeV})$.
} 


\section{TERMS OF LAUNCH AND MAIN OBJECTIVES OF THE FP-3 PROJECT}

After the collapse of the Soviet Union, the difficult economic situation in the country led to a significant reduction in both the number of existing scientific programs and opportunities for their implementation. The research in the field of controlled thermonuclear fusion (CTF), which required expensive operation of large energy- and resource-intensive research facilities, was no exception. The operation of the T-15, the world's largest superconducting tokamak by that time, was terminated and never resumed. Many Russian scientists were forced out of research or moved abroad; the development of CTF research infrastructure stopped. The only new tokamak built in Russia at that time was the GLOBUS-M, a compact (spherical) tokamak launched in 1999 and modernized in 2017 thanks to the enthusiasm and dedication of the team of the Ioffe Physical Technical Institute of the Russian Academy of Sciences (Ioffe Institute), as well as the support provided by the Russian Ministry of Education and Science. Today, the T-10 tokamak, a longlived record-breaker, is replaced at the National Research Center Kurchatov Institute (Kurchatov Institute) with the T-15MD tokamak, a larger divertor facility physically launched on May 18, 2021, which is to be completed with additional plasma heating and current generation systems within the implementation of FP-3.

The absence of its own national program for the development of thermonuclear fusion research, given that Russia is a participant in the development and construction of International Thermonuclear Experimental Reactor (ITER), the largest scientific and technological project of our time, was one of paradoxes of the post-Soviet era in the history of national science. FP-3 is the only comprehensive program for the development of the controlled thermonuclear fusion research ${ }^{2}$ over the past 30 years. The implementation of the federal project in our country will make it possible to take a significant step towards solving the problem of mastering and using thermonuclear energy, which is the most ambitious task set by humankind in the twentieth century (the evolution of ideas about the status and prospects of national CTF research can be traced by comparing the same-type publications [6, 7]). The layout of the federal project activities ensures the balanced progress towards thermonuclear power regardless of possible changes in the leadership of competing technologies as the world thermonuclear research develops.

Let us recall that, in fulfillment of the direction of the President of the Russian Federation No. Pr-104

\footnotetext{
${ }^{2}$ In 2010-2019, thermonuclear fusion research in Russia was partially funded by the federal special-purpose program "Next generation nuclear energy technologies 2010-2020" [5], including the construction of the T-15MD facility. ROSATOM was the main developer and state customer of this program.
}

dated January 21, 2016 on the elaboration and implementation of the national program for the development of controlled thermonuclear fusion and plasma technologies, the project of the national program for the development of controlled thermonuclear fusion and plasma technologies for the period up to 2035 was worked out by the Rosatom State Atomic Energy Corporation (ROSATOM) in collaboration with the NRC "Kurchatov Institute," the initiator of this program, and institutes of the Russian Academy of Sciences.

Based on the provisions of this program, the federal project "Development of controlled thermonuclear fusion and innovative plasma technologies" was created within the comprehensive program "Development of equipment, technologies, and scientific research in the field of atomic energy use in the Russian Federation for the period up to 2024" in accordance with Decree 270. This federal project includes a set of activities that provide the basis for the development of research infrastructure, accomplishment of research and developments, improvement of the information exchange system in the Russian Federation in the field of controlled thermonuclear fusion and plasma technologies by 2024 .

\section{THE MAIN TASKS AND STRUCTURE OF FP-3}

The implementation of FP-3 and DETS Program in general is meant to play the role of a powerful breakthrough factor stimulating the development of a wide range of industrial and technological segments of the Russian economy. The organization and implementation of a large-scale scientific and technological research within the DETS Program activities can become the "locomotive" for the industrial exploitation, implementation, and development of the advanced industrial technologies. Today, it is quite clear that the future progress in the field of thermonuclear research is hardly thinkable without:

- modernization of the existing and creation of new thermonuclear facilities and plasma test benches;

- development of the fusion reactor blanket nuclear technologies;

- development and implementation of the next generation physical and technological diagnostic tools;

- mastering and implementation of high-temperature superconductivity technology to create quasi-stationary magnetic systems;

- development of new structural materials and technologies;

- mastering and implementation of technologies for energy flux control and protection of the first reactor wall, non-induction plasma heating, and current maintenance; 
- development of a theoretical foundation for studying plasma-physical processes and developing programs for three-dimensional modeling of plasmaphysical processes of fundamental and practical value;

- wide implementation of state-of-art systems for the automated control and monitoring of experiments and technological systems; creation of intelligent control and analytical information systems;

- mastering and implementation of the dataflow processing of experimental data in the real-time mode.

At the same time, it is necessary to organize the process of continuous and systematic training of professional staff of the appropriate qualification and their retention in this field of science and engineering. FP-3 should be considered as the first stage of the accomplishment of the above tasks.

The FP-3 can be conventionally divided into five research areas.

\subsection{Research and Development of Basic Fusion Technologies}

We assume that "basic" fusion technologies are the technologies required to implement the magnetic confinement of high-temperature fusion plasma without regard to the ultimate goal of this confinement: the creation of a "clean" power reactor or thermonuclear neutron source (TNS), which is needed to implement the hybrid reactor concept. First, this involves the development of electromagnetic and corpuscular plasma heating systems with working parameters that meet modern ideas about the required power of such systems. In addition, it is planned to work out in detail the innovative technology of lithium protection of the first reactor wall and divertor, which supposedly is able to make the next important step toward achieving the reactor parameters of the plasma confined in tokamaks.

Despite the fact that FP-3 is mainly focused on the progress in the field of CTF using tokamaks, the development of elements of various systems related to the sphere of basic technologies is often easier and more evident in open configurations (plug traps), rather than in closed ones (tokamaks and stellarators). Moreover, the open traps equipped with innovative technological systems are capable to demonstrate a new quality of plasma confinement, which is a reason to continue relevant research, including the experimental ones.

\subsection{Research and Development of Hybrid Reactor Technologies and Systems}

In Russia, almost from their start in 1951, the research and development of CTF have been advanced in two directions: "pure" fusion energy and hybrid systems. The hybrid reactor concept should be consid- ered combined with the key problems of nuclear power industry to ensure its sustainable development and the fuel cycle closure. The main advantage of a hybrid fusion reactor over any other nuclear facility that provides the conversion of raw isotopes to fissile ones is the use of high-energy thermonuclear neutrons, which allows for a nearly tenfold increase in the intensity of production of new fissile isotopes from raw ones at the same power capacity of the facilities. This important quality implies that the presence of hybrid fusion reactors in the structure of a nuclear power system can be limited to a small fraction (less than 15\%), and at that the fuel supply problem can be solved completely. Fission reactors that are the backbone of the existing nuclear power industry will be provided with fissile isotopes produced in hybrid reactors. At the same time, hybrid reactors will be provided with tritium produced in fission reactors. The second traditionally discussed task for hybrid reactors: the highly efficient afterburning of minor actinides (MAs) accumulated during the operation of nuclear fission reactors, is also potentially solvable. However, this task for hybrid reactors has a competitive alternative-the molten salt reactors, so, in the opinion of the authors of this paper, hybrid reactors are less attractive in this sense. Note that the development of a research molten salt reactor as an MA afterburner prototype and some other supporting technologies is included in the federal project 4 "Development of new materials and technologies for advanced power systems" within the DETS program.

The relevance of the hybrid reactor concept is also based on the fact that the current level of knowledge and the available advances in the field of CTF are sufficient to create the "plasma core" of a hybrid reactor, which is a TNS, whose requirements for plasma parameters and structural materials are much lower than those of a thermonuclear power reactor, and the possibility of meeting these requirements has already been confirmed experimentally. Certainly, in addition to the creation of the TNS itself, there is a need for support works to confirm the operability of the blanket elements, technology for preparing/cleaning/recycling of its fuel composition, tritium cycle technology, and so on. These works are also planned within FP-3.

\subsection{Laser Thermonuclear Fusion and Technologies}

Although FP-3 was formed mainly as a project in the field of magnetic CTF, the decision was made to include some activities directly or indirectly related to inertial (specifically, laser) thermonuclear fusion, which implies an ignition (microexplosion) of a thermonuclear target in time shorter than the time of its fragments fly apart. Laser thermonuclear fusion developed as an alternative to the magnetic confinement method, provides, among other things, solutions to a number of special problems and progress in fundamental science, such as the study of the space-time 
structure of matter and unknown phenomena at the intersection of high-energy physics and physics of ultrastrong fields.

The activities anticipated in this direction within FP-3 are aimed at creating in the future a laser center based on a fundamentally new unique light source with power $0.1-0.2 \mathrm{EW}$, which hundreds of times exceeds the world best analogues. The task of creating such a source as a promising installation of the "megascience" class has not lost its relevance for the past decade [8].

\subsection{Development of Innovative Plasma Technologies, Including Preproduction Technologies}

This direction is embedded in FP-3 in order to demonstrate the productivity of fusion science on examples of devices and technologies suitable for industrial development already at the present stage. It is expected to bring a number of developments intended for application in engineering production, medical equipment, space, etc., based on the use of plasma technology to the preproduction and even production level. The parameters of the created devices will exceed the world level, which will secure the exportability of the developed equipment. They will be tested on the created or upgraded existing domestic test benches.

\subsection{Development of the Regulatory Framework for Thermonuclear and Hybrid Systems, Licensing Activities, Exchange of Scientific and Technical Information}

The inclusion of this direction in FP-3 is stipulated by the long-standing need to begin the systematic development of normative documents regulating the sphere of relations and responsibilities of users of CTF facilities, which becomes especially important when advancing into the real thermonuclear energy sector, whose facilities should be considered in the context of radiation and neutron safety, as well as nuclear safety in general. This work should be organized in collaboration with supervisory authorities and be based on interaction with the IAEA.

Along with the accomplishment of research and technological works, it is necessary to establish a fullfledged exchange of information and provide all participants of the project with a quick and informative access to both already existing and newly acquired data. The development and commissioning of the appropriate information system is also envisioned within FP-3.

\section{EXPECTED RESULTS AND KEY PARTICIPANTS OF FP-3}

The objectives set by the FP-3 federal project within the comprehensive DETS Program require a comprehensive approach to their solution. The FP-3 components include both research and development (R\&D), and construction, modernization, and/or technical re-equipment of CTF facilities in Russia.

Speaking about these facilities, we should first of all note the equipping with additional plasma heating and current generation systems of the T-15MD tokamak, the first Russian medium-scale ITER-like tokamak to become the main fusion research facility in Russia for the next decade.

T-15MD tokamak at the Kurchatov Institute will be equipped with a powerful gyrotron complex for electron cyclotron plasma heating that is traditional for Russian tokamaks. The gyrotrons will be developed by the Institute of Applied Physics, Russian Academy of Sciences (IAP, RAS) (up to five megawatt gyrotrons with operating frequency $112 \mathrm{GHz}$ ). A system of plasma injection heating of T-15MD will have the total power no less than $6 \mathrm{MW}$ (three $2 \mathrm{MW}$ injectors with the injected atom energy up to $75 \mathrm{keV}$ ). The development of the injector technology within FP-3 should result in creation of new devices: a neutral beam injector with the current no less than $150 \mathrm{~A}$ and energy of the atoms no less than $15 \mathrm{keV}$, and an ion source for multi-purpose atomic injectors with the power up to $7.5 \mathrm{MW}$ and the energy of the atoms within the beam no less than $500 \mathrm{keV}$. The developing devices are intended for use in the Tokamak with Reactor Technologies (TRT), which is discussed below. The main developer of the injector technology in the implementation of FP-3 is the Budker Institute of Nuclear Physics, Siberian Branch, Russian Academy of Sciences (BINP).

At the second stage of the technical upgrade, the T-15MD facility is to be equipped with the ion cyclotron and lower hybrid plasma heating systems with capacities 6 and $4 \mathrm{MW}$, respectively. If the modernization is successfully completed, the total power of the additional plasma heating systems of the tokamak will exceed $20 \mathrm{MW}$.

One of the important features of the T-15MD tokamak should be the anticipated duration of the working discharge up to $1 / 2 \mathrm{~min}$; t the same duration should be provided by all the auxiliary plasma heating and current drive systems. The energy flux density on the first wall will be $0.3 \mathrm{MW} / \mathrm{m}^{2}$, which will make it possible to perfect the technology for creating a closed lithium circulation loop in the tokamak chamber in a quasistationary operating mode in a real experiment under the conditions of both ohmic and noninduction heating.

The development of the ion cyclotron and lower hybrid plasma heating systems will be coordinated by the Ioffe Institute. An experimental antenna module prototype for the power up to $400 \mathrm{~kW}$ will be created and tested as a component element of an advanced antenna for the existing (T-15MD) and the future (TRT) Russian tokamaks. 
The developed technologies will be tested on the existing compact (spherical) tokamaks. In the experiments at the FT-2 facility, the central lower hybrid ion heating in dense (up to $10^{20} \mathrm{~m}^{-3}$ ) plasma of the compact tokamak will be carried out. At the Globus-M2 facility, the method for injecting lower-hybrid frequency range waves into plasma of the spherical tokamak to replace the 200-250 kA ohmic current will be tested for the first time in the world. In addition, the method for combined (injection and ion cyclotron) heating of plasma in the spherical tokamak will be tested to obtain the maximum plasma pressure and the ion temperature $T_{i}>2 \mathrm{keV}$; the power of injection of neutral atom beams will reach $1 \mathrm{MW}$.

The reconstructed strong-field tokamak complex at the State Research Center of the Russian Federation Troitsk Institute for Innovation and Fusion Research (TRINITI) (Troitsk, Moscow), including its power, vacuum, cryogenic, etc., engineering systems, will be the most large-scale facility, whose construction is planned within FP-3. This work will make it possible to base the TRT prototype, whose construction is seen to be the next important stage on the way to creating a hybrid reactor. New materials, a magnetic system based on HTS, hybrid blanket technologies, and experiments with energy conversion are, in short, the ideological basis of the TRT facility, whose project is to be developed by 2024 .

The mainstream research in the field of open systems will be provided by the development of the concept of gas-dynamic multiple-mirror trap (GDMT) expectedly combining the advantages of both multiple-mirror and gas-dynamic types of traps (see, for example, [9, 10]). By 2024, a pulsed GDMT model 10 meters in length will be created, in which we expect to suppress longitudinal losses in the multi-mirror mode at least three times. In experiments on the CAT (compact axisymmetric toroid) and SMOLA (spiral magnetic open trap) traps, the principles of high-pressure rotating plasma confinement in a helical magnetic field will be tested. Currently, the open traps applied to CTF are studied only at BINP.

Within FP-3, the construction of a laser center based on a fundamentally new subexawatt light source is planned to be initiated. In parallel, all basic elements of the unique laser complex will be developed, manufactured, and tested, including the modules with power $15 \mathrm{PW}$ each and the engineering infrastructure. A laboratory model of the driver module for the diodepumped laser thermonuclear fusion, unmatched in the world, will be created. The works in this direction will be carried out in collaboration with the following institutes of the Russian Academy of Sciences (RAS): Institute of Applied Physics (IAP RAS), Lebedev Physical Institute (LPI RAS), etc., and the ROSATOM institutions: Russian Federal Nuclear Center-All-Russian Scientific Research Institute of Experimental Physics (RFNC-VNIIEF), TRINITI, etc.
Note also the creation of a small training and demonstration MEPHIST tokamak at the National Research Nuclear University MEPhI designed for the professional training in CTF and automation of physical experiments, which should become a "trademark" of the MEPHIST facility [11, 12].

In addition to the abovementioned, during the FP-3 implementation, a number of engineering test benches are to be created or upgraded, which will be used to refine practical applications of the results of the accomplished studies. These results include the developed industrial installation prototypes for technological coatings for various purposes, technologies for creating radiation resistant electronic components based on single-crystal diamonds, and many other things. We should also highlight the high-temperature superconductors (HTS) and products based on them developed independently in Russia by the Efremov Institute of Electrophysical Apparatus (NIIEFA), Bochvar High-Technology Research Institute of Inorganic Materials (VNIINM), Kurchatov Institute, and Russian Scientific and Research Institute of the Cable Industry (VNIIKP).

A qualitative breakthrough will be made in the development and creation of the next generation powerful plasma rocket thrusters with parameter values 5-10 times higher than the parameters of the existing electrically powered spacecraft propulsion systems. This will include the development and testing of electrodeless plasma thruster laboratory prototypes with power values of 10 and $100 \mathrm{~kW}$, new magnetoplasmadynamic, Hall, and ion thruster prototypes with power ranging from 50 to $150 \mathrm{~kW}$, specific momentum values from 500 to $1500 \mathrm{~s}$, and service life no less than 20000 hours. Such devices are needed both for long-distance flights and for maintaining the parity in the near-Earth space. The centers of responsibility in the accomplishment of these works are the Kurchatov Institute, TRINITI, and the Keldysh Research Center.

The activities in the field of plasma technologies are aimed to strengthen the Russian positions in the development and production of gyrotrons that are powerful generators of microwave radiation used for cyclotron heating of plasma electrons, long-term generation of electric current in tokamaks, and other applications. New theoretical approaches will be created and new principles and schemes of implementation of powerful radiation sources, including those with controlled spectra, broadband ( $10 \%$ bandwidth), and frequency stabilized (with the relative frequency stability of $10^{-8}$ ) will be elaborated. Continuous sources of radiation for spectroscopy and medium diagnostics at the frequencies of $0.5-0.8 \mathrm{THz}$ with the power of at least $50 \mathrm{~W}$ will be developed. Prototypes of quasi-stationary and pulsed sources of electromagnetic radiation with up to multimegawatt power will be created for various purposes and spectral ranges. More than a dozen of institutions of different departmental 
subordination will participate in the activities in the field of applied plasma technologies.

Certainly, FP-3 activities are aimed not only at strengthening the material and technical base of the Russian research in the field of CTF and plasma technologies, but also at the accomplishment of experimental and theoretical research. The formulation of tasks and description of the anticipated results of this research are to be the subjects of separate publications.

\section{ORGANIZATION OF THE WORK, TERMS OF FUNDING AND TIMING OF THE PROJECT}

The scale and resource-intensiveness of the tasks stated in FP-3 and in the DETS Program in general require a very extensive funding and clarity in organizing the work, especially in view of the limited time frame of the Program implementation up to 2024 inclusive. According to Enactment of the Government of the Russian Federation No. 1019 dated July 10, 2020, the norms stipulated by the Regulation on the organization of project activities in the Government of the Russian Federation established by Enactment of the Government of the Russian Federation No. 1288 dated October 31, 2018 and applied to National Projects and Federal Projects within National Projects, are extended to the DETS Program and federal projects within this program. Therefore, the DETS Program has been equated to National Projects.

A.V. Novak, Deputy Chairman of the Government of the Russian Federation, is appointed to the position of Supervisor of the comprehensive DETS Program (the 14th National Project) on behalf of the Government of the Russian Federation; he heads the Project Committee of the DETS Program. A.E. Likhachev, Director General of ROSATOM, heads the National Project, and S.G. Novikov, State Secretary, Deputy Director General for Execution of State Powers and Budgeting of ROSATOM, is appointed the Administrator of the National Project. The Kurchatov Institute is assigned the head scientific organization of the DETS Program.

A similar management structure is implemented at a level of federal projects within the DETS Program. A.V. Novak is the Coordinator of FP-3, and Yu.A. Olenin, Deputy Director General for Science and Strategy, ROSATOM, is nominated the Head of the Federal Project. N.A. Ilyina, Director for Scientific and Technical Programs and Projects-Director of the Innovations Management Department at ROSATOM, is appointed the Administrator of the Project. V.I. Ilgisonis, Director for Scientific and Technical Research and Development at ROSATOM, is the Scientific Supervisor of the Project, and the Deputy General Director of TRINITI K.I. Ilyin is the director of R\&D projects within FP-3.
The DETS Program is funded by the federal budget and by ROSATOM own funds (more than $50 \%$ of the total amount). At the first stage, the approved amount of budget allocations for the DETS Program is 84 billion rubles, including about 32 billion rubles intended for FP-3. The additional budget funding of the DETS Program is currently (i.e., as of mid-July 2021) subject to approval. Similar to other national projects, the option of extending the DETS Program timeframe until 2030 with the proportional increase in the financial support is under consideration.

\section{CONCLUSIONS}

Along with the system research in plasma physics and plasma technologies, whose spectrum, as follows from the above, are rather wide, and with the development of the infrastructure supporting this research, the role of FP-3 is seen in laying the foundation for the next stage of movement towards the "thermonuclear El Dorado." Today, this stage appears to be the construction of the TRT, the facility that is largely based on the ITER project experience and new ideas that have emerged in the course of its implementation. Many FP-3 activities are aimed at the development of the scientific rationale and individual elements of this facility, whose construction project is to be completed in the next few years. Some of the results of this elaboration are published in the present issue of the journal, which, due to this fact, has a slightly more technical bias compared with the Plasma Physics Reports standards.

Nevertheless, the authors hope that the papers published in this issue will initiate active physical debates, including in the pages of the Plasma Physics Reports, and will ultimately form the basis for new proposals to be included in FP-3.

\section{OPEN ACCESS}

This article is licensed under a Creative Commons Attribution 4.0 International License, which permits use, sharing, adaptation, distribution and reproduction in any medium or format, as long as you give appropriate credit to the original author(s) and the source, provide a link to the Creative Commons licence, and indicate if changes were made. Theimages or other third party material in this article are included in thearticle's Creative Commons licence, unless indicated otherwise in a credit line to the material. If material is not included in the article's Creative Commons licence and your intended use is not permitted by statutory regulation or exceeds the permitted use, you will need to obtain permission directly from the copyright holder. To view a copy of this licence, visit http://creativecommons.org/licenses/by/4.0/. 


\section{REFERENCES}

1. Executive Order of the President of the Russian Federation No. 270 dated April 16, 2020.

http://www.kremlin.ru/acts/bank/45436. Cited August 15, 2021.

2. The Proryv Project of the State Atomic Energy Corporation ROSATOM. http://Proryv2020.ru. Cited August 15, 2021.

3. Multipurpose Fast Reactor MBIR. http://www.niiar.ru/mbir. Cited August 1, 2021; International Research Center based on the MBIR reactor. http://mbir-rosatom.ru. Cited August 1, 2021.

4. Fast Reactor BOR-60. http://www.niiar.ru/node/101. Cited August 1, 2021.

5. Executive Order of the Government of the Russian Federation No. 50 dated February 3, 2010.

6. E. P. Velikhov and V. P. Smirnov, Herald of the Rus. Acad. of Sciences 76, 245 (2006).

7. E. P. Velikhov and V. I. Ilgisonis, Herald of the Rus. Acad. of Sciences 91, 284 (2021).

8. The Exawatt Center for Extreme Light Studies. https://www.cremlin.eu/e17712/e60827/Passport_XCELS.pdf. Cited August 1, 2021.
9. A. Beklemishev, A. Anikeev, V. Astrelin, P. Bagryansky, A. Burdakov, V. Davydenko, D. Gavrilenko, A. Ivanov, I. Ivanov, M. Ivantsivsky, I. Kandaurov, S. Polosatkin, V. Postupaev, S. Sinitsky, A. Shoshin, et al., Fusion Sci. Technol. 63 (1T), 46 (2013).

10. D. Yakovlev, P. Bagryansky, A. Beklemishev, A. Burdakov, I. Chernoshtanov, A. Ivanov, M. Khristo, I. Kotelnikov, S. Polosatkin, V, Postupaev, V. Prikhodko, V. Savkin, D. Skovorodin, E. Soldatkina, A. Solomakhin, et al., in Conference Materials of the 28th IAEA Fusion Energy Conference, Virtual Event, 2020, Paper IAC/P4-7. https://conferences.iaea.org/event/214/contributions/17402/.

11. V. A. Kurnaev, G. M. Vorob'ev, V. E. Nikolaeva, S. A. Krat, et al., Nucl. Phys. \& Engineering 10, 24 (2019).

12. N. A. Kirneva, G. M. Vorob'ev, S. A. Ganin, A. S. Drozd, I. S. Kudashev, V. V. Kulagin, and V. A. Kurnaev, Probl. of Atom. Sci. and Techn., Ser. "Thermonuclear Fusion" 43 (3), 90 (2020). 